\title{
Estimation of Steam Turbine Shafts Fatigue Damage Caused by Torsional Vibrations
}

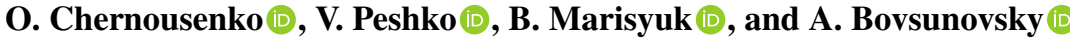

\begin{abstract}
In Ukraine, 74 power units with a capacity of 150-800 MW of thermal power plants out of 102 are on the verge of exceeding the park resource (220 thousand hours). Of these, 17 power units are close to the end the park resource, and 11 units have reached their estimated resource (100 thousand hours). Statistics of power plants accidents in different countries indicates that most of them are caused by the long term accumulation of fatigue damage. Among the main causes of fatigue damage are the pulsating of high-temperature steam flows in the turbine cylinders, transverse and torsional vibrations of shafts during long-term operation etc. This causes the development of computational and experimental methods for the determination of fatigue damage of turbine units' shafts under dynamic loads. The evaluation of fatigue damage of steam turbine K-200-130 shaft is based on the 3D finite element model. The calculations take into account experimentally determined fatigue properties of rotor steel. The fatigue damage as a result of torsional vibrations of turbine shaft caused by the abnormal operation of turbine generator is calculated. Zones of stress concentration in the rotating elements of the steam turbine type K-200-130 are established for various operating modes. The procedure to predict the effect of fatigue damage on the estimated resource of turbine unit is proposed.
\end{abstract}

Keywords Turbine shaft $\cdot 3 \mathrm{D}$ model $\cdot$ Finite element method $\cdot$ Fatigue damage $\cdot$ Torsional vibrations

\footnotetext{
O. Chernousenko · V. Peshko $(\varangle) \cdot$ B. Marisyuk Department of Cogeneration Installations of Thermal and Nuclear Power Plants, National Technical University of Ukraine "Igor Sikorsky Kyiv Polytechnic Institute", 37 Prosp. Peremohy, Kyiv 03056, Ukraine e-mail: vapeshko@gmail.com
}

\footnotetext{
A. Bovsunovsky

Department of Mechanical Engineering, Standardization and Certification of Equipment, National University of Food Technologies, 68 Volodymyrska Str., Kyiv, Ukraine
} 


\section{Introduction}

In the world energy sector, cases of brittle destruction of turbine units due to the fatigue damage are rare. However, they lead to catastrophic consequences with significant material losses. An example of such destruction is the accident at the Galatin power station (USA), when the rotor of the medium pressure cylinders of the turbine unit with a capacity of $225 \mathrm{MW}$ was broken into 30 parts [1]. A similar accident occurred in the United States in Pittsburgh [2]. The reason of these accidents was long-term accumulation of fatigue damage. For a similar reason, the turbine shaft of the Kashira thermal station with a capacity of 300 MW fell to pieces in 2004 [3].

The fatigue damage of steam turbine rotating elements during operation is dependent on the dynamic regimes of loading, which can cause transverse and torsional vibrations of the shaft. A lot of investigations were devoted to transverse vibrations of turbine shafts. At the same time, torsional vibrations are insufficiently studied. In general case, the reasons of turbine shafts torsional vibrations can be the reactive torque that occurs due to a short-circuit on generator, short circuit in power lines, connection of generator to power network with insufficient (rough) synchronization, touching of rotating parts to the turbine shell, all possible electromagnetic effects on generator [4-6]. As a result, the magnitude of the reactive torque can be by several times bigger than the magnitude of the torque at stationary regime of turbine operation.

The turbine generator short-circuit is very rare event, but under certain conditions it can cause the catastrophic failure of turbine shaft $[5,6]$. At the same time, the long-term accumulation of fatigue damage in turbine shaft is not possible because of this reason. However, the fracture analysis of fatigue cracks in the emergency destroyed shafts [1-3] revealed that cracks growth lasted several years.

The accumulation of fatigue damage in turbine rotating elements can be attributed to the frequent start-ups, which are usual for thermal power stations. The estimated number of such launches during the operation time of turbine units is nearly 2000. At each start-up at least one networking of turbine generator happens. The short-term reactive electromagnetic shaft's torque arises by reason of the difference of the phase shift angle between the vector of turbine generator electromotive force and the vector of power network voltage [7]. Thus, torsional vibrations of turbine shafts occur due to this reactive torque. In some cases, the intensity of torsional vibrations is high enough to be the reason of fatigue damage [8]. The number of cycles of vibration with maximal stress amplitude exceeding the fatigue limit of rotor steel at each startup of turbine can be in the range from tens to thousands. As a consequence, during the life-time of turbine operation fatigue damage gradually accumulates.

This work is the continuation of the research [7]. Unlike the research [7], the level of damping of shafts torsional vibrations were taken from the experimental investigation [9], which makes prediction of turbine shaft fatigue damage more realistic.

Given the above, it is evident that the study of influence of turbine shafts torsional vibrations, caused by the electromagnetic and mechanical processes in generator, on 
the stress-strain state (SSS) and fatigue damage of shafts is important. The object under investigation was steam turbine K-200-130.

\section{The Computational Model of Turbine Rotors in Three-Dimensional Setting}

Steam turbine of K-200-130 type consists of three rotors (high pressure, middle pressure and low pressure, respectively, that is HPR, MPR and LPR) and generator (TG). The three-dimensional model of the shaft line was created using the graphic editor SolidWorks. The model consisted of 177,538 finite elements, which are interconnected by 303,260 nodes (Fig. 1).

The geometric model of the shaft is developed in accordance with the drawings of the manufacturer and takes into account the main structural rotating elements of the turbine. At the same time, the geometric design of the blades and bandage connections was replaced by toroidal discs to reduce the time of numerical calculation. The sizes of these disks are specially selected in such way that their mass is equal to the mass of all blades and its mountings of this stage. Also, the outer diameter of the torus corresponds to the similar diameter of the blades. The studies conducted by the authors [10] showed that such a replacement is justified, since the error is about 5\%, and the calculation term is reduced significantly.

The shaft is loaded by static torques $T_{h p}, T_{m p}, T_{l p}$, caused by the pressure of steam respectively on HPR, MPR and LPR (Fig. 1). Torsional vibrations are excited by the

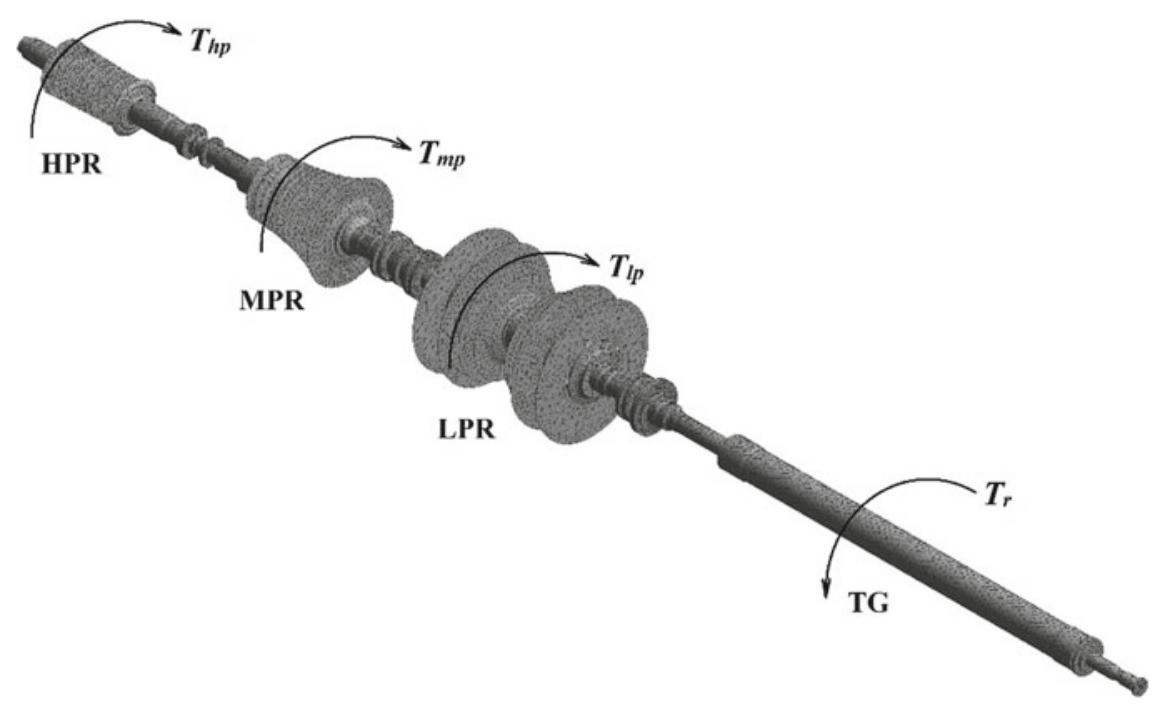

Fig. 1 3-D mesh of turbine K-200-130 shaft 
Fig. 2 Generator power dependence of damping characteristic of four turbine shaft torsional modes of vibration [9]

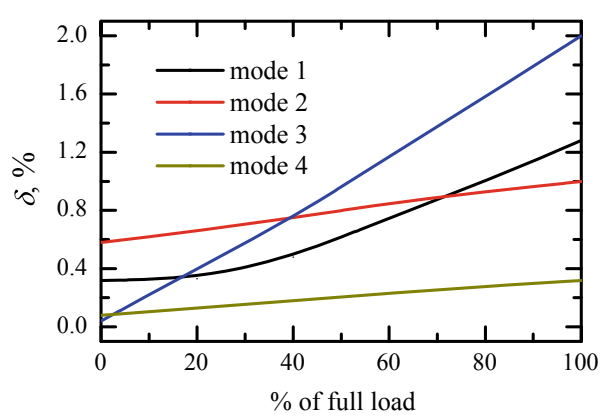

reactive torque $\left(T_{r}\right)$, which can be of electromagnetic or mechanical nature. Total static torque is the sum of static torques acting on rotors.

$$
T_{s t}=T_{h p}+T_{m p}+T_{l p}
$$

The reactive torque was assumed to be $\Pi$-shaped function [6] with short duration, which can simulate unsuccessful connection of generator to power network or mechanical interaction of turbine structural elements with the turbine shell. Its amplitude was related to the static torque in the following way [6]

$$
T_{r} / T_{s t}=3
$$

Damping characteristic of shaft was experimentally determined for different mode shapes (Fig. 2) [9]. In calculations damping in terms of logarithmic decrement there was accepted to be $\delta_{1}=1.28 \% ; \delta_{2}=1.0 \% ; \delta_{3}=2.0 \% ; \delta_{4}=0.32 \%$, where subscript means number of mode shape.

\section{Calculation of shaft's SSS at Stationary Mode of Operation}

This calculation did not take into account the pulsations of the steam flow, voltage fluctuations on the generator and in the electric network, because the influence of these factors on the SSS of the shaft is negligibly small.

The values of torque on rotors were assumed to be $T_{h p}=0.196 \mathrm{MNm}, T_{m p}=$ $0.291 \mathrm{MNm}$ and $T_{l p}=0.163 \mathrm{MNm}$. The sum of these moments is the nominal static torque $T_{s t}=0.65 \mathrm{MNm}$ acting in the area of coupling between the shaft of the steam turbine and the generator.

Figure 3 demonstrates the equivalent stresses by Mises in the stationary mode of operation of steam turbine that produces $200 \mathrm{MW}$ of electric power. As can be seen, the highest stresses are observed between the low pressure rotor and turbine generator. They are in the range of $150-170 \mathrm{MPa}$. The stresses that occur in the 


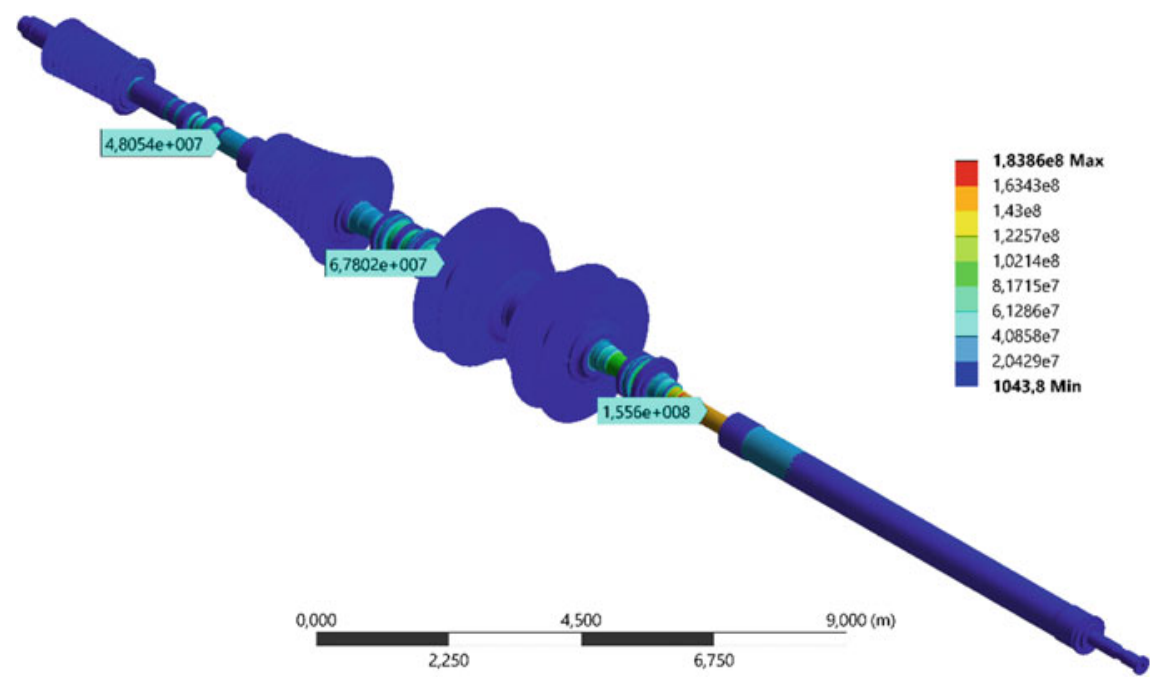

Fig. 3 Equivalent stresses of the shaft line of the K-200-130 turbine unit according to Mises at stationary mode of operation

area of the semi-rigid coupling between the MPR and LPR are in the range 1.4$72 \mathrm{MPa}$, and in the area between the HPR and MPR are in the range 3.4-53 MPa. The obtained stresses do not exceed the strength limit for $25 \mathrm{Cr} 1 \mathrm{Mo} 1 \mathrm{~V}$ steel, so the stationary operation does not lead to the significant accumulation of damage in the turbine shaft.

\section{Calculation of shaft's SSS Under Reactive Torque Loading}

The shaft's SSS was calculated for the forced vibrations caused by the short-term reactive torque and then-for the free vibrations, the reactive torque disappears. As it was mentioned above, the reactive torque was accepted to be $T_{r}=3 T_{s t}$. The duration of reactive torque was chosen so that the intensity of torsional vibrations was the highest, namely $0.02 \mathrm{~s}$.

The most dangerous areas of the turbine shaft are the coupling between HPR and MPR, as well as the sections between MPR and LPR and between LPR and TG. Figure 4 demonstrates the time dependence of equivalent stresses amplitudes for these areas as a result of action of the reactive torque.

The maximal amplitude of equivalent stresses between HPR and MPR is observed after $0.071 \mathrm{~s}$ from the beginning of the reactive torque and reaches $515 \mathrm{MPa}$. The maximal stress amplitude between MPR and LPR is observed on the fourth cycle of vibration at about the same time and reaches $495 \mathrm{MPa}$. Equivalent stress amplitude 

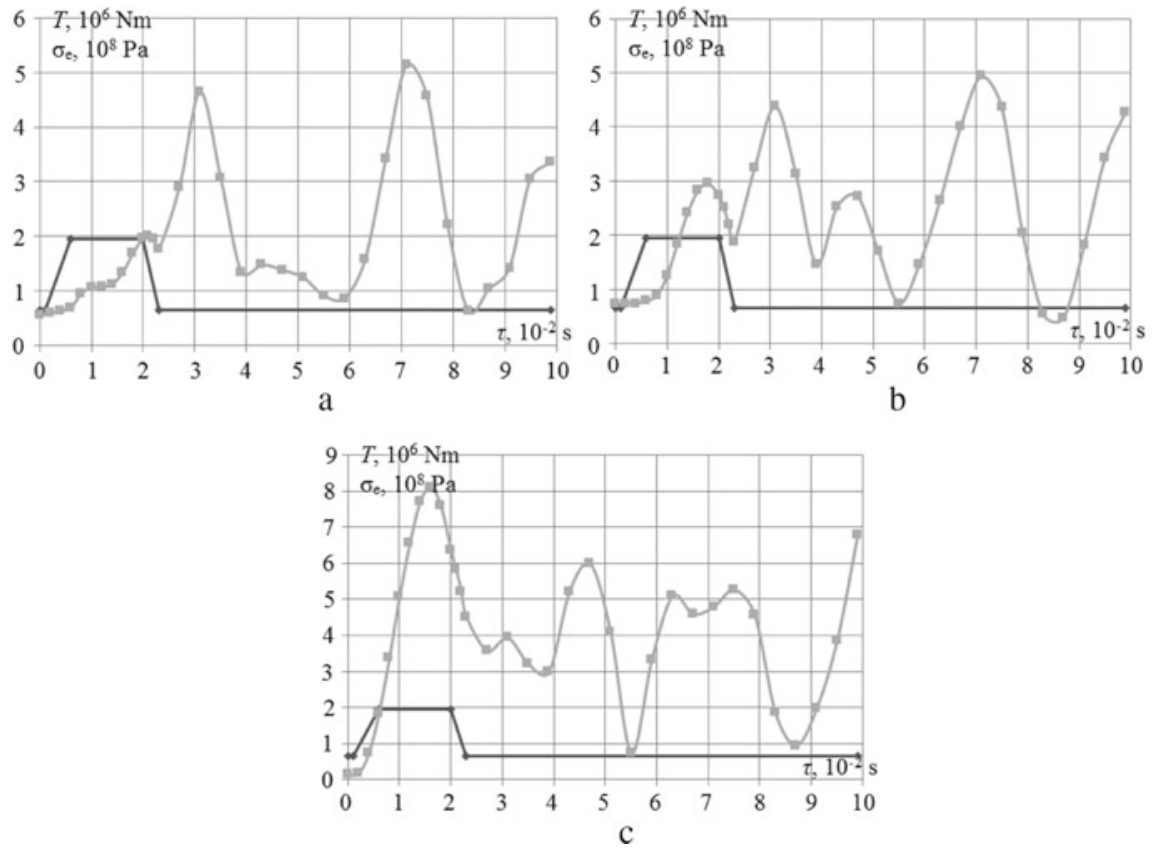

Fig. 4 Variation dynamics of the reactive moment (black line) and equivalent stresses (gray line) between HPR and MPR (a), MPR and LPR (b), LPR and TG (c) for the turbine K-200-130

between LPR and TG reach their maximal value after $0.016 \mathrm{~s}$ after the arising of torque and reaches $811 \mathrm{MPa}$. This value somewhat exceeds the ultimate strength of rotor steel $25 \mathrm{Cr} 1 \mathrm{Mo} 1 \mathrm{~V}$. Approximately in $4 \mathrm{~s}$ after cessation of the reactive torque, the vibrations completely damp.

\section{Effect of Reactive Torque on Fatigue Damage of Shaft}

The nature of reactive torque is very different. One of them, connected with mechanical problems, is not frequent event and hardly can be the reason of fatigue damage. Electromagnetic processes on generator happens every time during the networking. Taking into account that every networking of generator can cause intensive torsional vibrations of the steam turbine rotors, the amplitude of which exceeds the fatigue limit of rotor steel, several thousand of networking during lifetime of turbine unit causes long-term accumulation of fatigue damage.

The fatigue damage of the shaft in its most stressed areas (see Sect. 4) was estimated with usage of the Palmgren-Miner hypothesis [11, 12] 


$$
D=\sum_{i=1}^{n} \frac{1}{N_{i d}}
$$

where $n$ is the number of cycles with stress amplitude which exceeds the fatigue limit of rotor steel; $N_{i d}$ is the ultimate number of cycles till destruction.

Calculations of fatigue damage of the shaft was calculated with usage of the fatigue curve for the rotor steel $25 \mathrm{Cr} 1 \mathrm{Mo} 1 \mathrm{~V}$ [7]. The experiment was carried out at symmetric loading cycle and temperature $20{ }^{\circ} \mathrm{C}$. The effect of high temperature, scale factor and asymmetry of loading on the fatigue characteristics of rotor steel was taken into consideration by means of experimental coefficients. Woehler diagram in this case has the appearance.

$$
\tau_{\max }=K_{s} K_{a} K_{t}\left[\eta_{0}+\eta_{v}(N)^{c}+\eta_{u}(N)^{b}\right]
$$

where $\tau_{\max }$ is the amplitude of cyclic stress; $\eta_{0}=208,3 ; \eta_{v}=3176,2 ; \eta_{u}=$ $1,86 \cdot 10^{5} ; c=-0.3114 ; b=-0.8348 ; N$ is the number of cycles; $K_{s}$ is the scale coefficient; $K_{a}$ is the asymmetry coefficient; $K_{t}$ is the temperature coefficient.

Scale and temperature coefficients were taken from the experimental study [13], that is $K_{s}=0.58$ and $K_{t}=0.78$. The asymmetry coefficient was calculated with the equation [14]

$$
K_{a}=\frac{\sqrt{\tau_{-1}^{2}-\kappa^{2} \psi_{\tau}^{2} \tau_{m}^{2}}}{\tau_{-1}}
$$

where $\tau_{-1}$ is the fatigue limit (for the rotor steel $25 \mathrm{Cr} 1 \mathrm{Mo} 1 \mathrm{~V} \tau_{-1}=230 \mathrm{MPa}$ ); $\kappa=0.922 ; \psi_{\tau}=0.505[15] ; \tau_{m}$ is the mean stress.

The turbine shaft fatigue damage which is accumulated during operating time was calculated as a result of 2000 actions of the reactive torque (see Introduction), that is $D_{a c}=2000 D$. It is necessary to note, that failure takes place in case of $D_{a c}=1$.

The estimation of fatigue damage was based on the supposition that the reactive torque $t_{e l}$ lasting is distributed uniformly in the range of time $\Delta t_{e l}=t_{e l, K}-t_{e l, 1}\left(t_{e l, 1}\right.$ and $t_{e l, K}$ are the range limits). The averaged over this range fatigue damage was calculated according the following equation

$$
D_{a v}=\frac{\sum_{i=1}^{K} D_{a c, i}\left(t_{e l, i}\right)}{\Delta t_{e l}},
$$

where $D_{a c, i}$ is the accumulated fatigue damage during the action of the reactive torque $\left(t_{e l, i}\right)$.

Averaged fatigue damage was calculated only for the areas of the turbine shaft between HPR and MPR, and between MPR and LPR because for the considered parameters of the reactive torque the area between LPR and TG most probably destructs immediately. As can be seen from Fig. 5, the exhaustion of the turbine 
Fig. 5 Number of networkings dependences of averaged fatigue damage of turbine shaft in the area between HPR and MPR (red line) and between MPR and LPR (blue line)

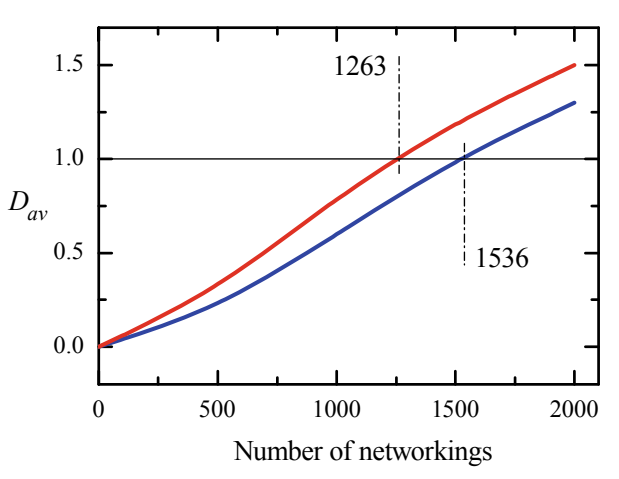

resource due to fatigue damage to the shaft occurs in 1536 actions of the reactive torque in the area between HPR and MPR and in 1263 actions of the reactive torque in the area between MPR and LPR.

It should be noted, that the above estimation of fatigue damage is somewhat simplified since it suggests that all 2000 actions of the reactive torque have the same parameters. Of course, real scenarios of loading are much more complex. The developed procedure can be applied for the evaluation of turbine shaft fatigue damage if the parameters of the reactive torque will be measured in operation of turbine units.

\section{Conclusions}

Long-term exploitation of turbine equipment of thermal power stations which undergoing to frequent start-ups and shut-downs gradually accumulates fatigue damage in the most stressed areas of turbine shaft. The reason of fatigue damage is the intensive transverse or torsional vibrations of the turbine rotating elements of different nature (see Introduction).

The experimentally-analytical procedure to estimate the fatigue damage of turbine rotors because of torsional vibration was developed. To apply this procedure in practice it is needed to know the intensity of turbine shaft torsional vibrations in operation of turbine unit. Modern methods of vibration measurement made it possible to solve this problem [16].

For the reactive moment with the parameters, which were assigned as an example to show the idea of the procedure, the most stressed area of the turbine shaft is the area between LPR and TG. The least stressed area is the area between MPR and LPR. In any case under the action of the reactive moment with the chosen parameters the resource of turbine unit substantially drops.

In general case the intensity of turbine shaft torsional vibrations is dependent on the magnitude, duration and shape of the reactive moment time function. 


\section{References}

1. Dorfman LS, Trubelja M (1999) Torsional monitoring of turbine-generators for incipient failure detection. In: Proceedings of the sixth EPRI steam turbine/generator workshop, pp 1-6. St. Louis, MO

2. DeForest DR, Grobel LP, Schabtach C, Seguin BR (1957) Investigation of the generator rotor burst at the Pittsburg station of the pacific gas and electric company. ASME Paper No. 57PWR-12, 3-14

3. Zagretdinov ISh, Kostyuk AG, Trukhnii AD, Dolzhanskii PR (2004) Failure of the 300 MW turbine unit of the state district power station at Kashira: causes, consequences and conclusions. Teploenergetika 5:5-15

4. Walker DN, Placek RJ, Bowler CEJ, White JC, Edmonds JS (1984) Turbine generator shaft torsional fatigue and monitoring. In: CIGRE session, pp 11-17

5. Barella S, Bellogini M, Boniardi M, Cincera S (2011) Failure analysis of a steam turbine rotor. Eng Fail Anal 18(6):1511-1519

6. Bovsunovskii AP, Chernousenko OYu, Shtefan EV, Bashta DA (2010) Fatigue damage and failure of steam turbine rotors by torsional vibrations. Strength Mater 42(1):108-113

7. Bovsunovsky AP (2015) Fatigue damage of steam turbine shaft at asynchronous connections of turbine generator to electrical network. Phys: Conf Ser 628

8. Kima C-K, Jang G (2007) Effect of an excitation system on turbine-generator torsional stress in an HVDC power system. Electr Power Syst Res 77:926-935

9. Steam turbine-generator torsional vibration interaction with the electrical network. Final Report. Electric power research institute. Palo Alto, California (2005)

10. Chernousenko O, Peshko V, Marisyuk B (2019) Rationalization of the approaches of numerical simulation of the geometrically complex rotating equipment of electrical stations. Power Eng: Econ Tech Ecol 3:30-36

11. Palmgren A (1924) Life of ball bearings. Z Ver Dtsch Ing 68:339-341

12. Miner MA (1945) Cumulative damage in fatigue. J Appl Mech 12:159-164

13. Kudryavtsev IV, Naumchenkov NE (1978) Fatigue strength characteristics of steel 25KhNZMFA in relation to absolute dimensions and stress concentrations. Strength Mater 10(4):386-392

14. Troshchenko VT (1969) A "scale effect" in tests of long-term strength. Strength Mater 1(1):2226

15. Troshchenko VT, Shestopal LR (1975) Criteria of torsional fatigue strength of metals. Strength Mater 7(2):127-131

16. Vaclavik J, Chvojan J (2017) Torsion vibrations monitoring of turbine shafts. In: Francesco I (ed) Procedia Structural Integrity 5. Elsevier, Amsterdam, pp 1349-1354 